\title{
ANALISIS PENGELOLAAN LINGKUNGAN PERMUKIMAN DI PINGGIRAN SUNGAI KAHAYAN KELURAHAN PAHANDUT KOTA PALANGKA RAYA
}

\author{
Analysis of Settlement Environment Management on the Kahayan River Side \\ Pahandut Village Palangka Raya City
}

Milka

Universitas Muhammadiyah Palangkaraya, Palangka Raya, Central Kalimantan, Indonesia

email:

milkaniez22@gmail.com

Kata Kunci:

Analisis

Pengelolaan

Lingkungan

Keywords:

Analysis

Management

Environment

Accepted

Januari 2020

Published

April 2020

\section{Abstrak}

Pengelolaan permukiman di pinggiran sungai Kahayan kelurahan pahandut kota palangka raya merupakan sebagian cara yang dilakukan oleh masyarakat dan di bantu pihak pemerintah untuk menjaga kualitas air bersih pada lingkungan sungai dan mengurangi pembuangan sampah rumah tangga ke sungai dengan cara pemberian tampat sampah pada masyarakat, pembuatan MCK / sanitasi dan septictank komunal.

Untuk tinjauan pustaka mengenai pengelolaan permukiman, teori yang digunakan teori milik George R Terry, Sedangkan indikator yang digunakan untuk mengetahui proses terjadinya pengelolaan permukiman yakni mengunakan pendekatan perencanaa, pengorganisasian, pelaksanaan, dan pengawasan atau yang di kenal dengan sebutan POAC.Metode peenelitian yang digunakan yaitu deskriptif kualitatif. metode pengumpulan data menggunakan observasi, wawancara, dan dokumentasi. Hasil penelitian mengungkapkan bahwa proses pengelolaan permukiman di pinggiran sungai Kahayan kelurahan pahandut kota palangka raya berjalan sudah cukup baik, hanya saja pemanfaatannya kurang maksimal dari segi Proses pengelolaan permukiman yang terdiri dari tahap perencanaan, pengorganisasian, pelaksanaan, dan pengawasan.

\begin{abstract}
Management of settlements on the edge of the Kahayan river, pahandut, Palangkaraya city, is part of the way done by the community and assisted by the government to maintain the quality of clean water in the river environment and reduce the disposal of household waste to the river by providing slagging to the community, making MCK / sanitation and communal septic tank. For a literature review on settlement management, the theory used by George R Terry's theory, while the indicators used to determine the process of settlement management that is using the approach of planning, organizing, implementing, and supervising or known as POAC.

The research method used is descriptive qualitative. data collection methods using observation, interviews, and documentation.
\end{abstract}

The results of the study revealed that the process of settlement management in the Kahayan river bank, pahandut, palangkaraya city, was running quite well, only that the utilization was not optimal in terms of the settlement management process which consisted of the planning, organizing, implementing, and controlling stages 


\section{PENDAHULUAN}

Perkembangan kota dan meningkatnya jumlah penduduk menyebabkan permukiman baru berkembang hingga di sepanjang sungai. Hal demikian menyebabkan sungai kehilangan fungsinya serta kualitas lingkungannya menurun. Banyaknya pemukiman yang dibangun di sepanjang sungai menyebabkan sungai beralih fungsi dan sempit.

Sayangnya, manfaat atau fungsi sempadan sungi tersebut selama ini seolah di abaikan oleh pemerintah ataupun pemerintah daerah. Hal tersebut dapat kita lihat langsung secara kasat mata di sepanjang sungai kaahayan yang sudah banyak dibangun permukiman masyarakat dan menjadi lahan bagi masyarakat untuk memenuhi perekonomian kelurga dengan cara membuat tambak ikan.

Pengelolaan permukiman merupakan salah satu upaya terwujudnya hidup aman, tentram, dan sejahtera. Begitu juga dengan pembangunan perumahan dan pemungkiman merupakan upaya untuk memenuhi salah satu kebutuhan dasar manusia, sekaligus untuk meningkatkan mutu lingkungan hidup, memberi arah pada pertumbuhan wilayah, memperluas lapangan kerja serta menggerakan perekonomian dalam rangka peningkatan dan pemerataan kesejahteraan rakyat. Sesuai dengan Pasal 33 Ayat 3 Undang-Undang Dasar Tahun 1945 menyatakan bahwa :

"Bumi, air dan kekayaan alam yang terkandung didalamnya dikuasai oleh Negara dan dipergunakan sebesar-besarnya untuk kemakmuran rakyat".

Hal ini menjelaskan bahwa selain memiliki kewajiban dalam mensejahterakan rakyatnya Negara juga memiliki hak untuk mengatur bumi; air dan tanah beserta isinya.

Wewenang pemerintah dalam penataan ruang yang tercantum dalam Undang-Undang Republik Indonesia tahun 2007 Penataan Ruang Pasal 8 yang menyatakan bahwa:

\section{Penyelenggaraan penataan ruang.}

Penyelenggaraan penataan ruang adalah kegiatan yang meliputi peraturan, pembinaan, pelaksanaan, dan pengawasan.
2. Pelaksanaan penaataan ruang.

Pelaksanaan penataan ruang adalah upaya pencapaian tujuan penataan ruang meliputi pelaksanaan, perencanaan tata ruang, pemanfaatan ruang, dan pengembalian pemamfaatan ruang.

3. Pelaksanaan penataan ruang dengan pendekatan nilai strategis kawasan.

Pelaksanaan penataan ruang dengan pendekatan nilai strategis aksudnya adalah untuk mengembangkan, melestarikan, melindungi dan/atau mengoordinasikan keterpaduan pembangunan nilai strategis kawasan yang bersangkutan demi terwujudnya pemanfaatan yang berhasil guna,berdaya guna, dan berkelanjutan.

Undang-Undang Nomor 23 Tahun 2014 tentang Pemerintah Daerah, maka setiap daerah diberikan kewewenangan yang lebih luas dalam mengatur urusan rumah tangganya sendiri yakni kewewenangan dalam menentukan kebijakan pemerintahan dibidang termasuk didalam penataan ruang, hal ini juga disebut didalam Undang-Undang Nomor 26 Tahun 2007 tentang Penataan Ruang pada pasal 5 ayat (3) yang mengatur penataan ruang berdasarkan wilayah administratif terdiri atas penataan ruang nasional, penataan wilayah provinsi dan penataan ruang wilayah kabupaten kota.

Pada pasal 4 peraturan pekerjaan umum dan perumahan rakyat di jelaskan bahwa sempadan dan tepi palung sungai, untuk sungai tidak bertanggul. Garis sempadan sungai bertanggul di dalam kawasan perkotaan ditentukan paling sedikit berjarak 3 (tiga) meter dari tepi luar kaki tanggul sepanjang alur sungai. Larangan mendirikan bangunan juga diatur dalam pasal 157 Undang-Undang Lembaran Negara Tahun 201I Nomor I Tambahan Lembaran Negara Tahun 200II Nomor I tentang 
perumahan dan kawasan permungkiman yang berisi

"setiap orang yang dengan sengaja
membangun perumahan dan/atau
pemukiman di tempat yang berfotensi dapat
menimbulkan bahaya bagi barang atau
orang sebagaimana dalam pasal l 40
dipidana dangan pidana kurungan paling
lama I(satu) tahun atau denda paling
banyak Rp. 50.000.000,00(lima puluh juta
rupiah)."

Berkaitan dengan lingkungan, di dalam pasal I ayat (I) Undang-Undang Lembaran Negara dan Tambahan Lembaran Hidup merupakan kesatuan ruang dengan semua benda, daya, keadaan, dan makhluk hidup, termasuk manusia dan perilakunya, yang mempengaruhi alam itu sendiri, kelangsungan perikehidupan dan kesejahteraan menusia serta makhluk hidup lainnya. Untuk itu lingkungan harus dijaga dan dirawat secara terus menerus.

Berdasarkan latar belakang masalah di atas, maka penulis merumuskan permasalahan penelitian sebagai berikut: Bagaimana Analisis Pengelolaan Lingkungan Permukiman Di Pinggiran Sungai Kahayan Kelurahan Pahandut Kota Palangka Raya ?

\section{METODOLOGI}

Metode penelitian yang digunakan dalam penelitian ini adalah kualitatif yang digunakan untuk meneliti pada objek yang alamiah, dimana peneliti adalah sebuah instrument kunci, sedangkan teknik pengumpulan data dilakukan dengan metode wawancara, analisi data bersifat induktif, dan hasil penelitian kualitatif lebih menekankan pada makna dari pada generalisasi Menurut Sugiyono (2010)

Sumber data yang digunakan sumber data primer dan sekunder dengan tekbik pengumpulan data melalui, Observasi, Wawancara Mendalam, dan Dokumnentasi, yang berkaitan dengan penelitian untuk mendapatkan data yang akurat.

\section{HASIL DAN PEMBAHASAN}

Proses pengelolaan permukiman di Pahandut Seberang Kota Palangkaraya yang di lakukan oleh masyarakat setempat yang tergabung dalam kelompokkelompok seperti swadaya masyarakat (KSM) dan BKM dan di bantu oleh pihak pemerintah melalui berbagai program, seperti program NUSP dan program KOTAKU.

Ada empat indikator dalam proses pengelolaan, keempat indikator tersebut yaitu : perencanaan, pengorganisasian, pelaksanaan, dan pengawasan, berikut penjabaranya secara lebih mendalam.

\section{Perencanaan (planning)}

Perencanaan (planning) adalah pemilihan fakta-fakta dan usaha menghubungkan fakta satu dengan lainnya, kemudian membuat perkiraan dan peramalan tentang keadaan dan perumusan tindakan untuk masa yang akan datang yang sekiranya diperlukan untuk mencapai hasil yang dikehendaki.

Tujuan perencanaan adalah:

a. Mengurangi atau mengimbangi ketidakpastian perubahan perubahan diwaktu yang akan datang.

b. Memusatkan perhatian kepada sasaran.

c. Mendapatkan/menjamin proses pencapaian tujuan terlaksana secara ekonomis.

d. Memudahkan pengawasan

Dalam proses perencanaan pengelolaan permukiman di sempadan sungai Kahayan kelurahan pahandut seberang dengan konsep lingkungan melibatkan masyarakat setempat dimana pada tahap ini masyarakat diminta berkumpul untuk rapat menentukan permasalah lingkungan apa yang paling urgent, ketika sudah ditentukan permasalahannya masyarakat yang tergbung dalam kelompok swadaya masyarakat (KSM) membuat proposal berupa dokumen RPLP, dokumen ini nantinya akan diserahkan ke pihak 
lebih tinggi melalui tim fasilitator untuk di verifikasi

Ketika sudah ditetapkan permasalahan yang paling urgent untuk di selesaikan barulah pemerintah melakukan tindakan perbaikan peningkatan kualitas infrastruktur tersebut. Dengan demikian pemerintah lebih mudah dalam melakukan perbaikan mana yang harus diutamakan yang berhubungan dengan kebutuhan masyarakat.

\section{Pengorganisasin (organizing)}

Pengorganisasian (organizing) diartikan sebagai kegiatan mengaplikasikan seluruh kegiatan yang harus dilaksanakan antar kelompok kerja dan menetapkan wewenang tertentu serta tanggung jawab sehingga terwujud kesatuan usaha dalam pencapaian tujuan yang telah ditetapkan.

Tujuan pengorganisasian diatas menurut Laksmi dkk. adalah :

a. Mendelegasikan tugas-tugas untuk menjaga keseimbangan beban kerja dalam suatu organisasi yang sehat.

b. Memberikan batasan wewenang untuk melaksanakan tugas sehingga setiap orang dapat mengambil keputusan sesuai dengan diharapkan.

c. Memastikan tanggung jawab dalam jabatanjabatan perorangan untuk mencegah seseorang melemparkan kesalahan kepada pihak lain, atau mengkambinghitamkan orang lain.

d. Memudahkan koordinasi, tidak hanya mengkoordinasi sumber daya manusia tetapi juga sumber daya lainnya, seperti anggaran, fasilitas dan peralatan.

e. Memudahkan motivasi dan moral pekerja.

Proses pengorganisasian atau pembagian tugas dalam pelaksanaan pengelolaan permukiman di pahandut seberang dengan konsep lingkungan dikatakan sudah terorganisasi dengan baik, semua terlihat pada saat pelaksnaan dilapangan dimana setiap masyarakat bekerja mengerjakan tugas masing-masing, seperti pihak dinas PU bertugas dalam hal pengawasan pada pelaksanaan pembuatan jalan, pihak KSM bertugas untuk melakukan pembuatan jalan maupun perbaikan rumah masyarakat.

Proses pembagian tugas ini dilakukan pada saat rapat yang dlakukan oleh ketua BKM bersama masyarakat yang tergabung dalam sebuah kelompok masyarakat (KSM) dan tim fasilitator dimana setiap kelompok mempunyi tugas dan tanggung jawab masing-masing untuk di kerjakan di lapangan.

Dengan adanya pembagian tugas ini akan memudahkan masyarakat dalam melaksanakan tugas dan akan mempermudah pada saat proses pertanggung jawaban pada saat semua pekerjaan sudah selesai dikerjakan.

\section{Pelaksanaan (actuating)}

Proses pelaksanaan dalam hal pengelolaan permukiman di pahandut seberang yang terus berjalan yaitu program untuk perbaikan jembatan atau jalan lingkungan dan pemberian Tempat sampah, ketika program ini telah selesai baru akan di lanjutkan ke permukiman yang berada di sempadan sungai dan di daerah aliran sungai (DAS), program perbaikan jalan lingkungan sendiri untuk di Pahandut Seberang sudah di lakukan dari tahun 2014 melalui program NUSP, akan tetapi semua perbaikan infrastruktur tersebut hanya untuk bangunan yang berada di sebelah jembatan tidak untuk yang berada di tepi sungai karena untuk daerah itu merupakan daerah yang tidak boleh ada bangunan.

Pada saat ini proses pengelolaan untuk di Pahandut Seberang masih mengarah pada perbaikan-perbaikan infrastruktur pada kawasan lingkungan berupa jalan lingkungan dan perumahan 
masyarakat belum menjalar ke area zona hijau seperti sempadan sungai

Pada tahap pelaksanaan seperti pembuatan jalan lingkungan yang berupa jembatan tidak mengalami kesulitan karena dalam pembelian barang yang lebih dipreoritaskan adalah kecukupan bahan untuk pembuatan jembatan, karena sebelum adanya bantuan pemerintah jalan di daerah pahandut seberang ini hanya terbuat dari kayukayu yang mudah rapuh, sedangkan jembatan merupakan fasilitas yang sangat dibutuhkan masyarakat di pahandut seberang pada saat itu.

Selain perbaikan jalan lingkungan dan rumah masyarakat pemerintah juga memberikan tempat sampah, sanitasi dan septictank komunal yang pipanya tersambung ke rumah-rumah warga pada masyrakat di Pahandut seberang, dengan adanya pemberian tempat sampah ini diharapkan masyarakat yang berada di area sempadan sungai tidak lagi membuang sampah mereka ke sungai.

Untuk di daerah pahandut seberang pada saat ini yang paling diutamakan adalah pemberian tempat sampah dan sanitasi pada masyarakat, karena dengan adanya persampahan dan sanitasi yang sesuai standar akan membuat masyarakat lebih peduli pada kesehatan, serta dengan adanya persampahan dan sanitasi akan membuat lingkungan menjadi lebih bersih dan pencemaran pada lingkungan lebih terkendali.

Akan tetapi, pada kenyataanya di daerah pahandut seberang masih banyak ditemukan sampah dimana- mana padahal sudah di sediakan tempat sampah, hal ini menunjukkan masih banyak masyarakat yang tidak menyadari dampak bahaya dari sampah- sampah rumah tangga yang mereka buang sembarangan, dan MCK yang telah dibangun oleh pemerintah melalui program NUSP tidak dimanfaatkan dengan baik oleh masyarakat setempat, mereka lebih suka menggunakan MCK pribadi ketimbang MCK umum.

\section{Pengawasan (controling)}

Pada tahap pengawasan pelaksanaan pekerjaan pengelolaan permukimanseperti perbaikan jalan ligkungan mapun perbaikan rumah masyakat di pahandut seberang dengan konsep lingkungan melibatkan pihak dinas pekerjaan umum (PU) dan tim fasilitator.

Semua pekerjaan diawasi oleh dinas PU dan Tim Fasilitator, tujuan pengawsan ini agar semua pekerjaan berjalan sesuai dengan yang direncakan pada saat rapat bersama dengan masyrakat. Pengawasan dilakukan dari mulai proses pembelian barang sampai tahap akhir pelaksanaan pekerjaan di awasi oleh dinas PU dan tim fasilitator bertujuan agar masyarakat bekerja sesuai arahan yang sudah di kasih tau, dan hasil pekerjaan infrastrukturnya sesuai dengan standar kualitas yang sudah di tentukan.

\section{KESIMPULAN}

Proses pengelolaan lingkungan permukiman di sempadan sungai Kahayan kelurahan pahandut seberang kota palangkaya berjalan sudah cukup baik, semua terlihat dari adanya bantuan pembuatan jalan lingkungan yang sudah dilakukan pemerintah sejak tahun 2014 dan tiap tahun dilakukan perbaikan guna mempermudah aktifitas masyarakat dan diberikannya bantuan berupa Sanitasi/ MCK, penyediaan tempat sampah dan septictank dengan tujuan masyarakat lebih perduli pada lingkungan dan kesehatan.

Berikut tahapan proses pengelolaan lingkungan permukiman di pahandut seberang

I. Tahap perencanaan, yaitu pada tahapan ini masyarakat yang tergabung dalam Kelompok Swadaya Masyarakat (KSM) di suruh menyusun dokumen Rencana Penataan Lingkungan Permukiman (RPLP)

2. Tahap pengorganisasian, yaitu pada tahap ini ketua Badan Keswadayaan Masyarakat (BKM) 
melakukan rapat untuk pembagian tugas atau tanggung jawab yang di damping Tim Fasilitator.

3. Tahap pelaksanaan, yaitu dengan melaksanakan pembangunan infrastruktur di pahandut seberang, yang dilakukan oleh masyarakat/KSM, dan di damping Tim Fasilitator (Dinas PU).

4. Tahap pengawsan, yaitu proses dalam mengawasi setiap pelaksanaan yang di lakukan masyarakat/KSM mulai dari proses pembelian barang sampai pada tahap akhir pekerjaan infrastruktur.

\section{SARAN}

I. Saran Praktis

a. Perlunya dilakukan sosialisasi pada masyarakat mengenai pentingnya menjaga lingkungan agar terus bersih dan sehat.

b. Untuk dinas yang menangani pengelolaan lingkungan hendaknya lebih bisa memberikan pemahaman pada masyarakat tentang larangan membuat permukiman di sempadan sungai.

c. Perlunya dibuat aturan zonasi dan diperdekan agar pelenggaran pemanfatan ruang dapat di kurangi.

2. Saran Teoritis

a. Peneliti menyarankan agar ada yang melakukan penelitian serupa dan dengan perspektif yang sama. Karena kondisi pengelolaan bisa saja berubah ketika pergantian pemimpin

b. Perlu adanya peningkatan sistem pengawasan pada daerah-daerah yang berfotensi untuk dibuat permukiman liar seperti daerah sempdan sungai.

\section{REFERENSI}

Afifuddin. 2010. Pengantar Administrasi Pembangunan Konsep Teori dan Implementasinya di Era Reformasi. Bandung: Alfabeta.

Bungin, M Burhan. 2006. Metodologi Penelitian Kualitatif: Komunikasi, Ekonomi, dan Kebijakan Publik serta Ilmu-ilmu Sosial Lainnya. Jakarta: Kencana.

Janthy, Trilusianthy Hidajat. 2014. Model pwngelolaan kawasan permukiman berkelanjutan di pinggiran kota metropolitan jabodetabek.

Laksmi, dkk. 2008. Manajemen Perkantoran Modern. Jakarta: Penaku

Maryono. 2013. Pengelolaan Kawasan Sempadan Sungai. Yogyakarta: Gajah Mada University Press

Moleong, Lexy J. 2006. Metode Penelitian Kualitatif. Bandung: PT. Remaja Rosdakarya.

M. Yunus Wahid. 2014. Pengantar Hukum Tata Ruang , Jakarta: Kencana

Novianti, Listyaningrum. 2017. Pengelolaan Sempadan Sungai Code sebagai upaya pelestarian ekosistem daerah aliran sungai di kota Yogyakarta dan sekitarannya, seminar nasinal III.

R. Terry, George. 2006. Prinsip-Prinsip Manajemen. Jakarta: Bumi Aksara

Salim, Peter dan Yenny Salim. 2002. Kamus Bahasa Indonesia Kontemporer. Jakarta:Modern English Press.

Sastra M. Suparno \& Endy Marlina. 2006. perencanaan dan pengembangan perumahan Yogyakarta: C.V Andi Offset

Sudarto. 2002. Metode Penelitian Filsafat. Jakarta: Raja Grafindo Persada.

Sugiyono. 2014. Memahami Penelitian Kualitatif. Bandung: Alfabeta.

Sugiyono. 2010. Metode Penelitian Kuantitatif Kualitatfi dan R\&D. Bandung: Alfabeta. 
Sukarna. 20II. Dasar-Dasar Manajemen.Bandung: CV

Mandar Maju

Undang-Undang Nomor 26 Tahun 2007 tentang

Penataan Ruang pada pasal 5 ayat (3)

Undang-Undang Lembaran Negara Thun 20II Nomor

I Tambahan Lembaran Negara Tahun 20II

Nomor I tentang perumahan dan kawasan permukiman. 